\title{
Impact of the New Delhi metallo-beta-lactamase on beta-lactam antibiotics
}

This article was published in the following Dove Press journal:

Infection and Drug Resistance

24 August 2015

Number of times this article has been viewed

\section{Monika T Zmarlicka' \\ Michael D Nailor ${ }^{2}$ \\ David P Nicolau ${ }^{3}$}

'Department of Pharmacy, Hartford Hospital, Hartford, ${ }^{2}$ School of

Pharmacy, Department of Pharmacy Practice, University of Connecticut, Storrs, ${ }^{3}$ Center for Anti-Infective Research and Development, Hartford Hospital, Hartford, CT, USA
Correspondence: David P Nicolau Center for Anti-Infective Research and Development, Hartford Hospital, 80 Seymour Street, Hartford, CT 06102, USA

$\mathrm{Tel}+$ I 860545394 I

Fax + I 8609723992

Email david.nicolau@hhchealth.org

\begin{abstract}
Since the first New Delhi metallo-beta-lactamase (NDM) report in 2009, NDM has spread globally causing various types of infections. NDM-positive organisms produce in vitro resistance phenotypes to carbapenems and many other antimicrobials. It is thus surprising that the literature examining clinical experiences with NDM does not report corresponding poor clinical outcomes. There are many instances where good clinical outcomes are described, despite a mismatch between administered antimicrobials and resistant in vitro susceptibilities. Available in vitro data for either monotherapy or combination therapy does not provide an explanation for these observations. However, animal studies do begin to shed more light on this phenomenon. They imply that the in vivo expression of NDM may not confer clinical resistance to all cephalosporin and carbapenem antibiotics as predicted by in vitro testing but other resistance mechanisms need to be present to generate a resistant phenotype. As such, previously abandoned therapies, particularly carbapenems and beta-lactamase inhibitor combinations, may retain utility against infections caused by NDM producers.
\end{abstract}

Keywords: carbapenemase, metallo-beta-lactamase, resistance

\section{The New Delhi metallo-beta- lactamase carbapenemase}

Beta-lactamase production is a common mechanism of resistance, particularly among Gram-negative organisms. ${ }^{1}$ Carbapenemases are distinct among the beta-lactams; in addition to being able to hydrolyze most penicillins and cephalosporins, they are also able to hydrolyze the carbapenems. There are two biochemically distinct classes of carbapenemases: the serine beta-lactamases and the metallo-beta-lactamases (MBLs). The fundamental difference between these two classes resides in their hydrolytic mechanisms and rate of hydrolysis. The serine beta-lactamases rely on serine residues within the active site for hydrolytic activity, whereas MBLs rely on zinc ions. Because of these mechanistic differences, these enzymes are inhibited differently; serine beta-lactamases can be inhibited by beta-lactamase inhibitors (such as clavulanic acid), whereas MBLs are inhibited by agents that can chelate divalent cations (such as EDTA). Several MBLs have been described in the literature. ${ }^{2}$ The imipenemase (IMP) variety of MBLs was among the earlier beta-lactamases in the class to be identified in the 1980s in Japan. Since their discovery, several IMP variants have been described. Verona integron-encoded metallo- $\beta$-lactamase (VIM)-type enzymes are another type of MBL with several described variants, and SPM-type enzymes are another example of MBLs that have been discovered. The New Delhi metallo-beta-lactamase (NDM) is the most recently discovered, globally distributed enzyme. ${ }^{2}$ This review will focus on the impact of the NDM enzyme on beta-lactam antibiotics. 
NDM was first reported in the literature in 2009 in a Klebsiella pneumoniae isolate and was referred to as NDM-1. ${ }^{3}$ This particular isolate was found on a urine culture from a male patient in Sweden who had traveled to and had been hospitalized in India. Further investigation of the $b l a_{N D M-1}$ gene found in this isolate revealed that NDM-1 bound and hydrolyzed all beta-lactams, with the exception of aztreonam. To date, there have been 13 variants of NDM that have been identified: NDM-1 to -14 (NDM-11 was not assigned to any unique variant). ${ }^{46}$ The variants arise from site mutations within the gene encoding the beta-lactamase. The location of the mutation on the gene seems to predict rates of hydrolysis. Many of the variants, such as NDM-2 and NDM-3, share similar hydrolytic activity with NDM-1, as the mutations are not located in the active site of the enzyme. Some variants, such as NDM-4, do have genetic alterations in the active site and have been observed to have increased hydrolytic activity toward carbapenems. ${ }^{7}$ As summarized in Table 1, NDM-1 is the most common variant in cases of clinical infections and unless otherwise noted will be the focus of this paper.

NDM was named so after its place of origin: New Delhi, India. ${ }^{3}$ Organisms carrying genetic material for NDM have been found to be very capable of transferring genes encoding NDM, as well as any other resistance genes the pathogen may be carrying. ${ }^{8}$ The ease with which the genes are transferred is concerning, and the implications for dissemination of NDM are immense. Indeed, since its discovery, it has spread across the globe. ${ }^{9}$ The most recently published surveillance study reported a total of 135 NDM isolates from around the world. ${ }^{9}$ Despite the fact that about half of the isolates came from India, the study established the presence of NDM-producing organisms in other parts of the world, such as Vietnam, Serbia, the Philippines, the Middle East, Guatemala, and the USA. Reports of NDM-producing organisms have also surfaced from Pakistan, ${ }^{10}$ the UK, ${ }^{10}$ Japan, ${ }^{11}$ the Netherlands, ${ }^{12}$ and Australia. ${ }^{13}$ Figure 1 depicts the geographical distribution of NDM; the areas where NDM producers are most commonly isolated are located on the Asian continent. ${ }^{4}$ Outbreaks have also been reported around the world in areas such as the UK and the Middle East. The clinical cases outlined in Table 1 also help demonstrate the wide spread of NDM producers. A variety of non-beta-lactam antimicrobials are sometimes utilized, including as a part of combination therapy. However, often these organisms producing NDM are resistant to many other antimicrobials, if not all antimicrobials, which may limit non-beta-lactam options. Additionally, the antibiotics that retain activity have high rates of side effects or have limitations in drug delivery, colistin, and fosfomycin, respectively. Given the worldwide spread and the broad resistance patterns detected, it is important to fully explore all our therapeutic options, including the clinical impact of these enzymes on beta-lactam antibiotics.

\section{Identification of NDM - microbiological challenges in phenotypic identification}

The modified Hodge test was a recommended screening tool by the Clinical and Laboratory Standards Institute (CLSI) for carbapenemase-producing organisms. ${ }^{14}$ This test, however, only screens for a phenotype, and therefore will not distinguish between the various types of carbapenemases. MBLs in particular can be difficult to detect using these methods, and as such, pose unique challenges in the laboratory. ${ }^{15}$ The Carba NP test has also recently been developed for better carbapenemase detection ${ }^{16}$ and is now a preferred method of detection per CLSI standards. ${ }^{17}$ Identification methods utilizing chelating agents have also been developed to help better identify MBLs. ${ }^{14}$ These methods look for either additive or synergistic effect when a chelating agent is added to a hydrolyzable beta-lactam. The chelating agent, by binding zinc ions that are necessary for hydrolytic activity, prevents MBL from taking action on the beta-lactam. Once an MBL is identified, to further determine which specific MBL is present requires genotypic identification.

\section{Clinical experience with NDM-producing pathogens}

Clinical experience with treating infections caused by NDM producers is limited, making it difficult to fully assess the impact of NDM on clinical outcomes. A study evaluating neonatal sepsis in a level III neonatal intensive care unit (NICU) surprisingly insinuated that infection with an NDM producer did not confer higher mortality as compared to infections caused by other resistant pathogens. ${ }^{18}$ The study identified 105 blood cultures from a 5-year time span that were found to have either cephalosporin resistance genes or carbapenem resistance genes. The only carbapenemase identified in this cohort was NDM; all the isolates had various combinations of different extended-spectrum beta-lactamases (ESBLs) and AmpC beta-lactamases. Fifteen isolates were found to produce NDM-1. Cefotaxime combined with either amikacin or gentamicin were the preferred empirical antibiotics within the first year of the 5-year study period, which was switched to piperacillin/tazobactam combined with amikacin. Severe infections warranting broader coverage were treated with combinations of ofloxacin, colistin, and meropenem. This broader therapy was more favored as empirical therapy after 


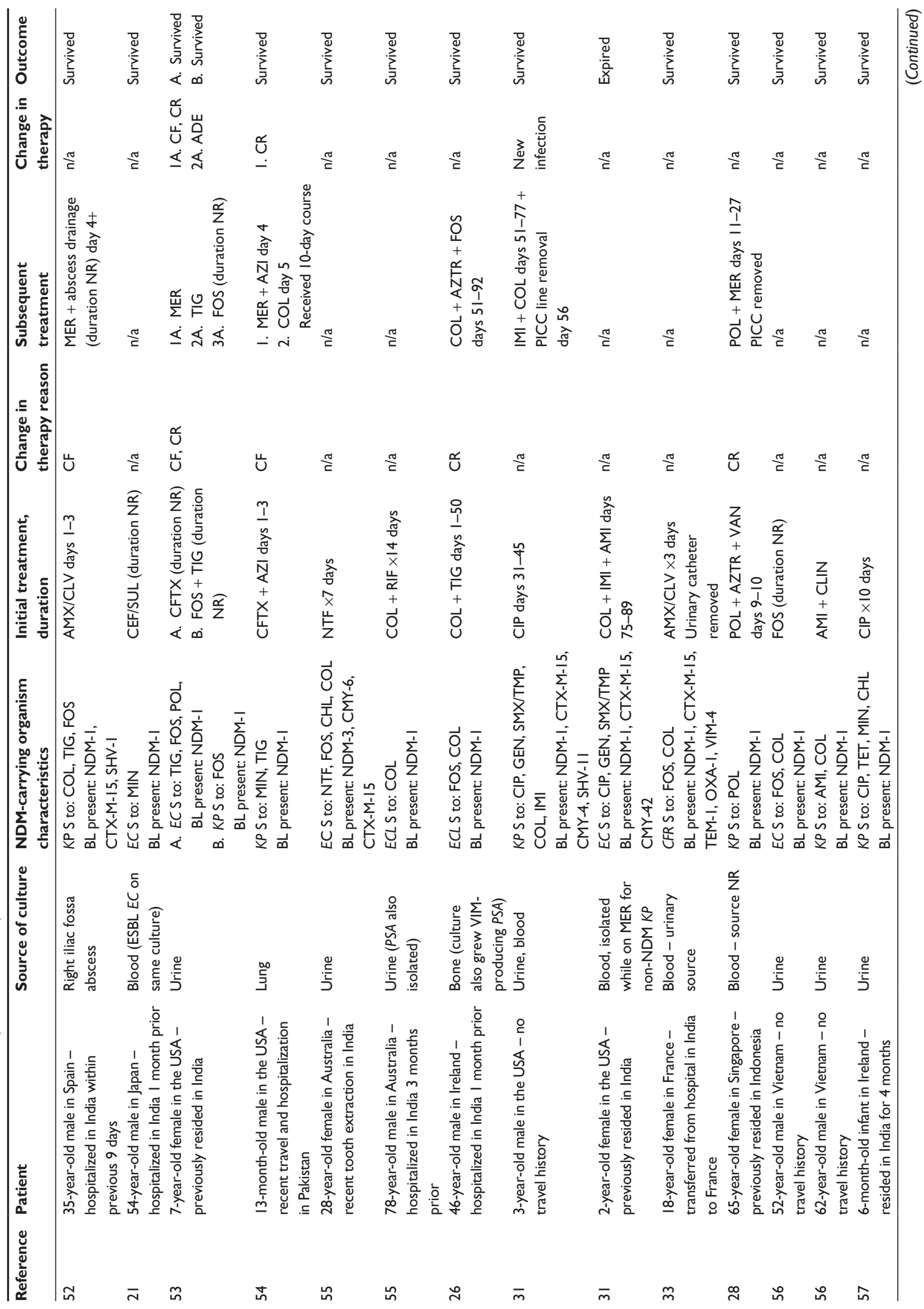




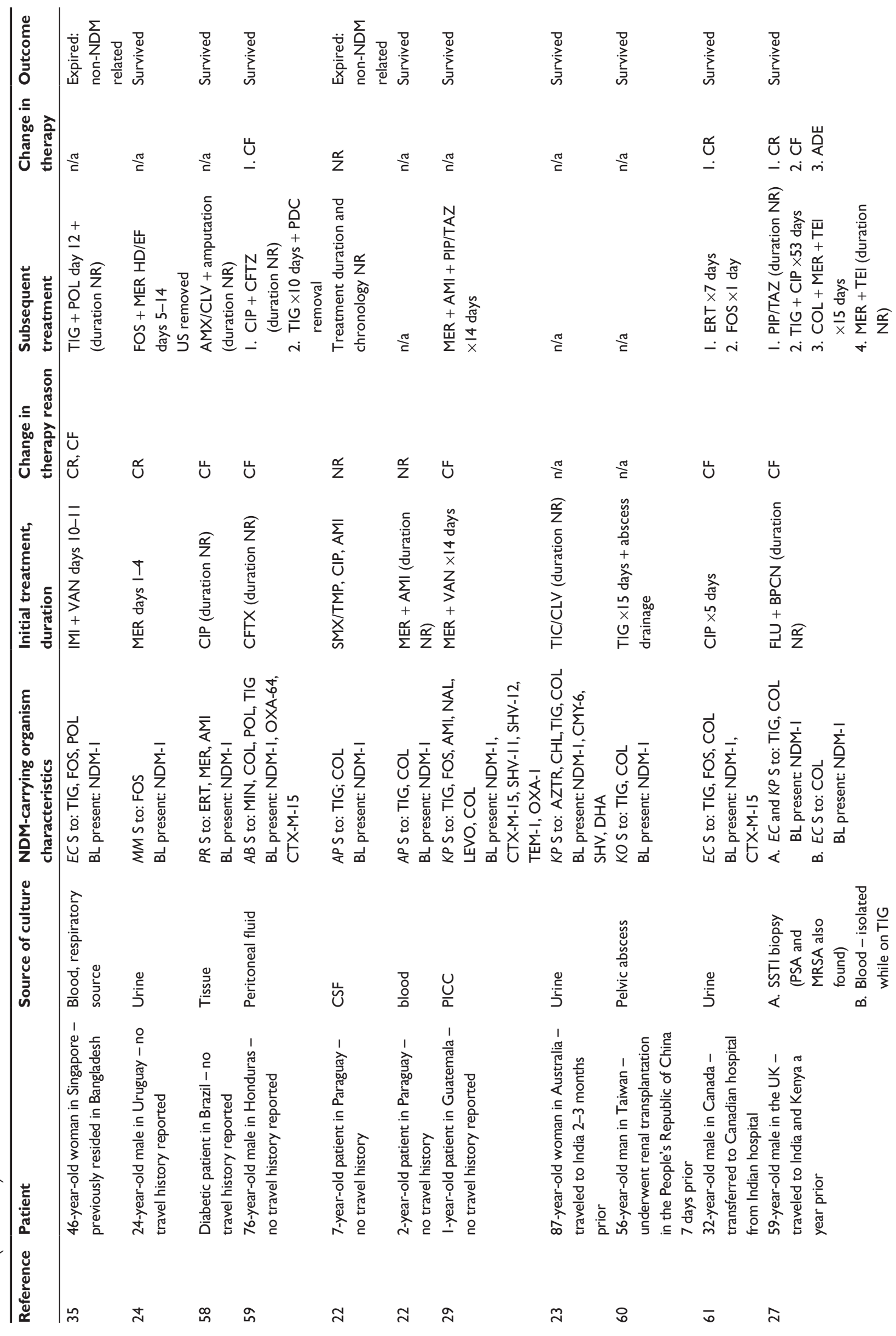




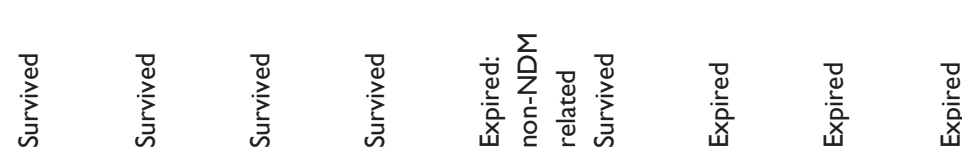

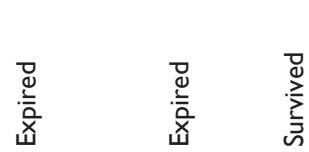

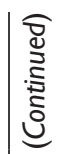

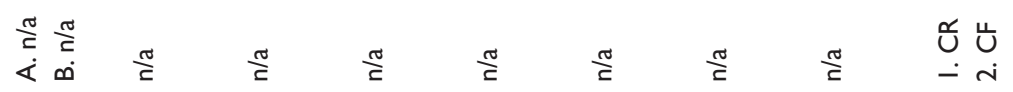

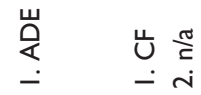

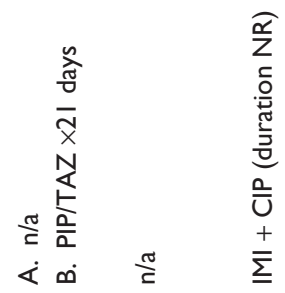

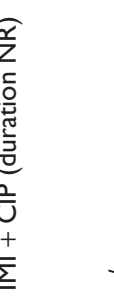

ฮี บิ

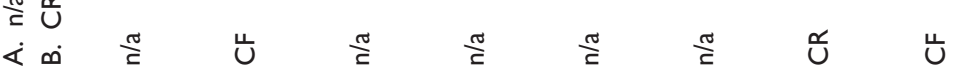

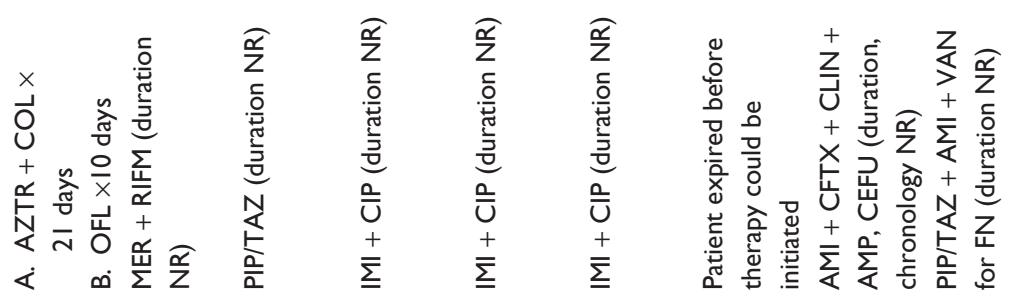

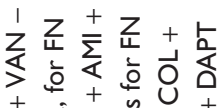

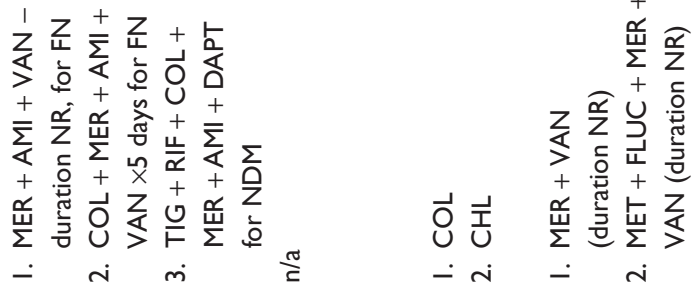

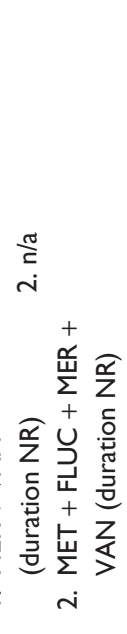

$\stackrel{U}{\Xi} \quad \frac{\infty}{Z}$

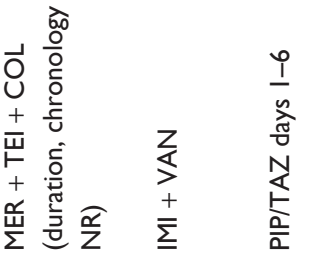

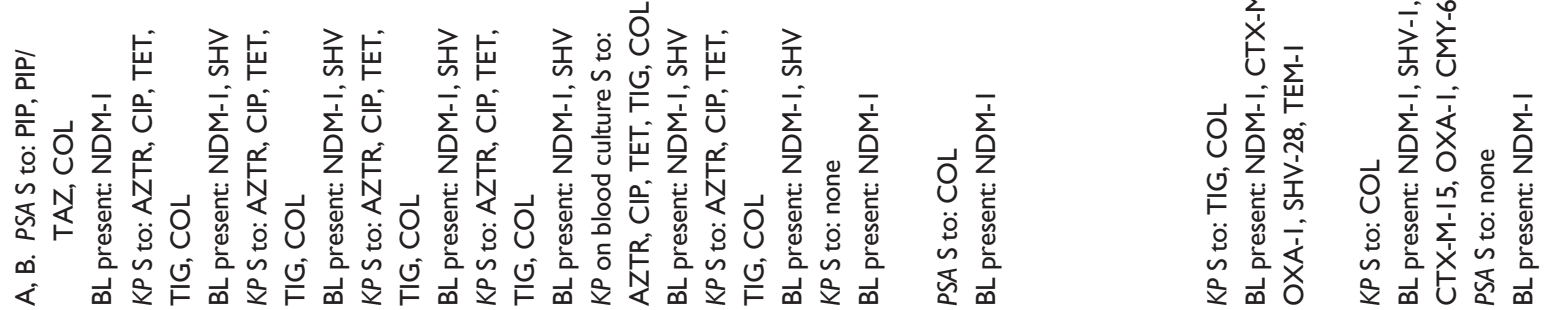

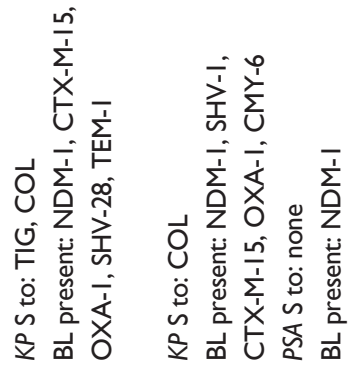

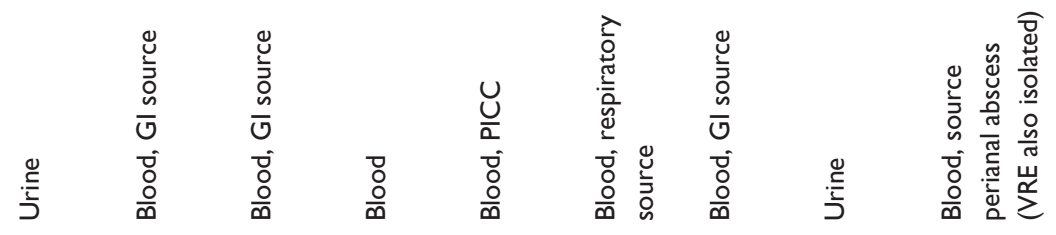

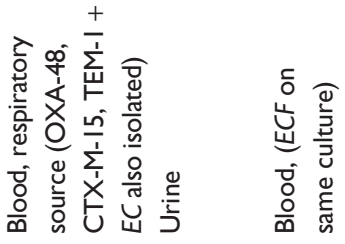

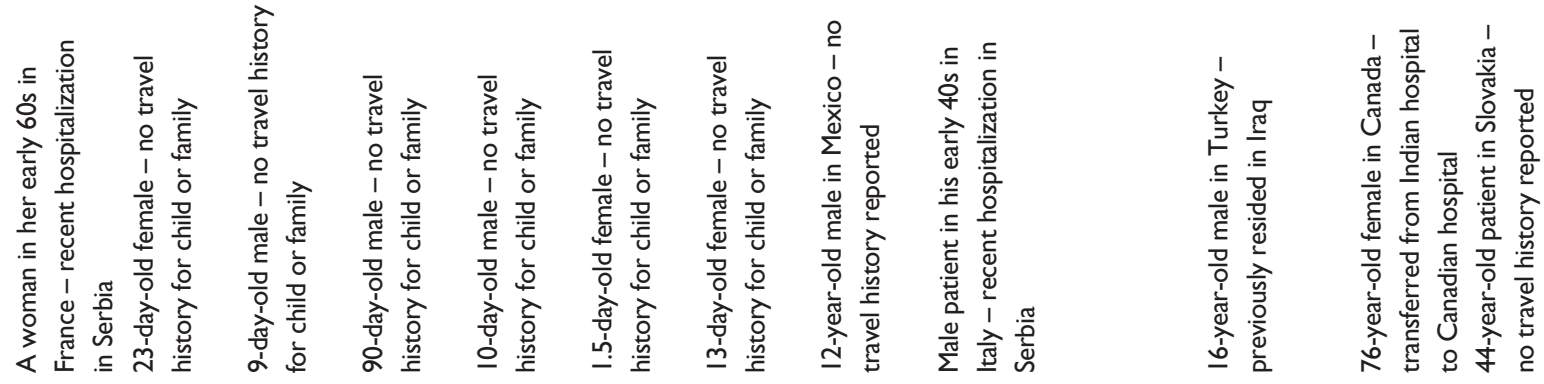

$\stackrel{2}{2}$

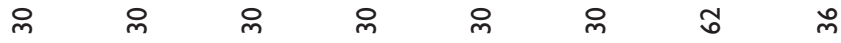

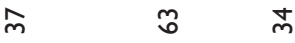




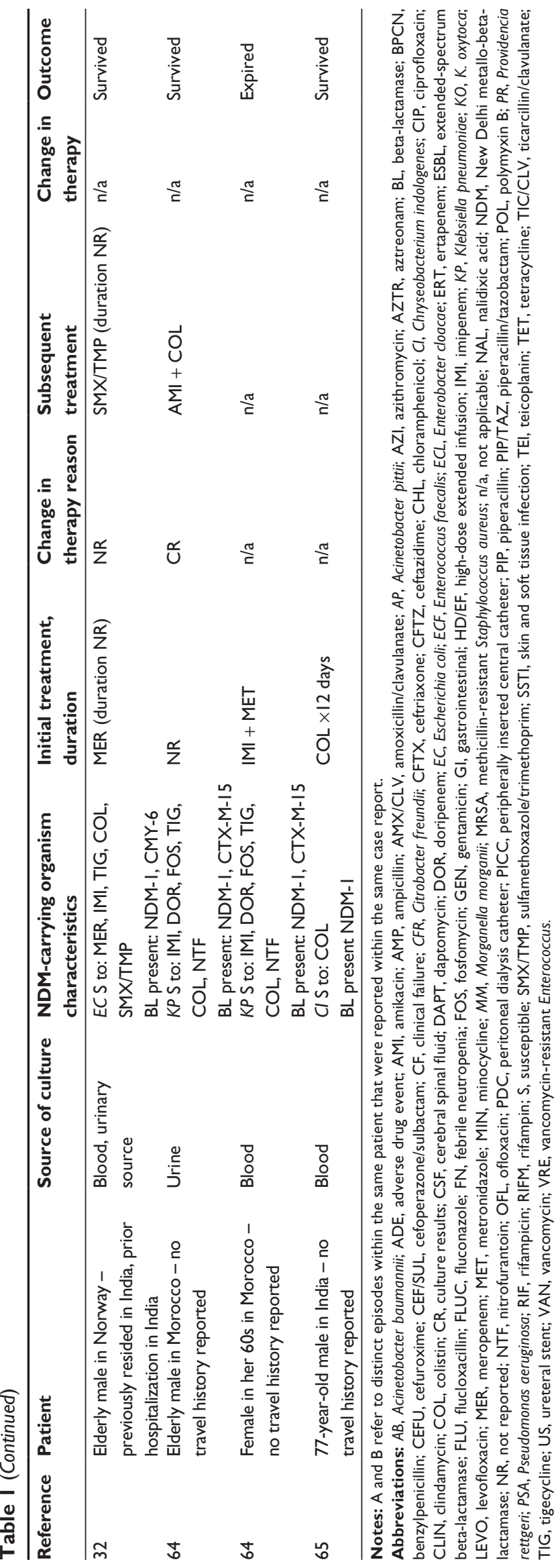

carbapenem resistance trends were identified. Looking closer at the antibiotics used against NDM-producing isolates, there are a substantial number of patients who received antimicrobials without in vitro activity against the isolate and survived to be discharged from the NICU. Interestingly, mortality rates for neonates with bacteremia caused by an NDM producer (13.3\%) versus those with a non-NDM producer were not different. A similar result was seen in another observational study evaluating bloodstream infections caused by K. pneumoniae producing VIM, another MBL; production of VIM was not found to be associated with an increase in mortality. ${ }^{19}$ These observations are unexpectedly positive, given the additional in vitro resistance that is conferred by these enzymes. However, with mortality rates for $K$. pneumoniae carbapenemase infections being reported from clinical experiences to be between $42 \%$ and $53 \%,{ }^{20}$ the mortality rate seen with NDM seems staggeringly low. These studies call into question the magnitude of impact on clinical outcomes associated with MBL, and particularly, NDM production.

Most data describing clinical outcomes with infections caused by NDM producers are available in various case reports, summarized in Table 1. These case reports also tend to report good outcomes despite mismatches with therapy and susceptibilities. Specifically, there were instances in which appropriate therapy per culture was never reported to be initiated, and the patient's infection resolved. ${ }^{21-23}$ There were also cases where therapy was switched to provide antimicrobials to match susceptibility results despite a lack of reported clinical failure on the "inappropriate" antimicrobials. ${ }^{24-26}$ Combination therapy at some point during treatment was commonly described and often included a carbapenem in the regimen. ${ }^{24,27-30}$ Of the 18 patients with NDM producers identified on blood culture, seven patients had isolates susceptible to antibiotics received during the course of treatment and survived..$^{27,28,30-32}$ Five patients had pathogens isolated on blood culture that were not susceptible to any antibiotics received during the course of treatment and survived, three of which received a carbapenem..$^{21,22,30,31,33,34}$ Of the six patients with bacteremia who expired, ${ }^{30,31,35-37}$ only one had an NDM producer isolated that was not susceptible to any of the antibiotics received during the course of treatment. ${ }^{31}$ One of the patients expired before antibiotics were initiated, ${ }^{30}$ and the remaining four patients who expired had an NDM-producing pathogen on blood culture that was considered susceptible to antibiotics received during the course of treatment. ${ }^{30,35-37}$ Two of these patients expired due to non-NDM related causes, ${ }^{30,35}$ and the remaining two patients had undergone stem cell transplantation approximately $2-3$ weeks prior to expiring. ${ }^{36,37}$ 


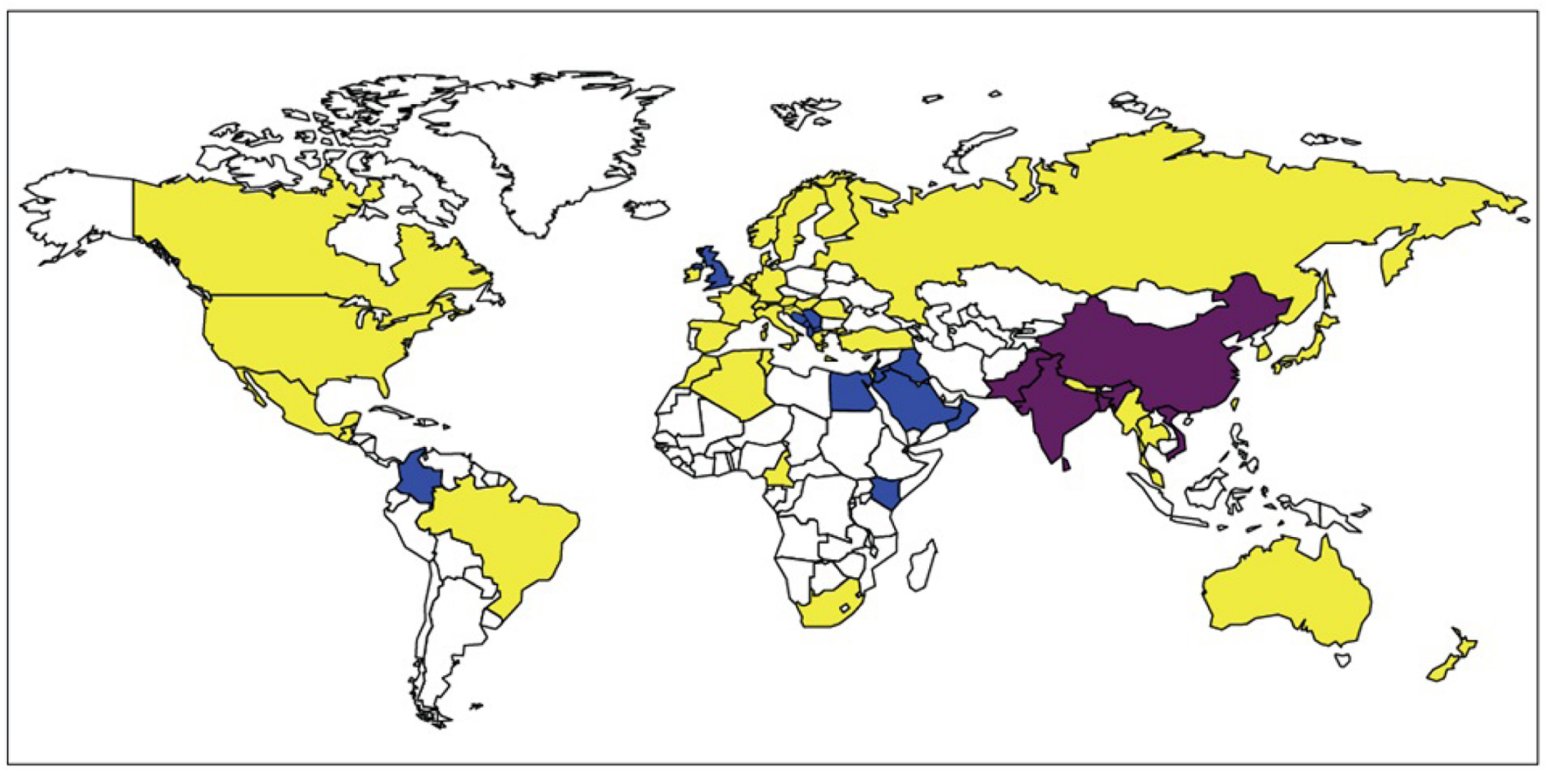

High prevalence of NDM producers (endemicity)

Outbreaks and interregional spread of NDM producers

Sporadic description of NDM producers

Figure I Geographic distribution of NDM producers.

Note: Reproduced with permission from the Hindawi Publishing Corporation. Copyright (C 20I4. Dortet L, Poirel L, Nordmann P. Worldwide dissemination of the NDMtype carbapenemases in gram-negative bacteria. Biomed Res Int. 2014;2014:249856. ${ }^{4}$

Abbreviation: NDM, New Delhi metallo-beta-lactamase.

The cases described in Table 1 ultimately describe a broad range of patients and infection types with surprisingly positive outcomes. Although a trend toward positive outcomes exists, there are many other patient-specific factors that contribute to the patients' success rate, including underlying immune function and disease states, ability to drain/remove abscesses and infected necrotic tissues, and the management of invasive devices that might be colonized with the pathogen. These factors preclude definitive statements from being made about such therapies. However, these results further call into question the repercussions to be expected with NDM producers on patient outcomes and deserve further investigation in a controlled setting to investigate the possible rationale(s) for the discrepancies.

\section{In vitro susceptibilities}

Literature reporting in vitro susceptibility of NDM producers often describes resistance to many antimicrobials and does not offer an explanation for the clinical successes recounted. A surveillance study gathering NDM-carrying clinical isolates from around the world characterized resistance patterns from 135 isolates. $^{9}$ Of the varieties of NDM, NDM-1 was most commonly seen, accounting for $96.3 \%$ of the isolates. Only levofloxacin (12.7\% susceptibility) and amikacin (16.4\% susceptibility) had any activity against the isolates; neither cephalosporins, piperacillin/tazobactam, nor ampicillin/ sulbactam displayed any in vitro activity. Based on this study, carbapenems did not appear to offer any substantial activity against these isolates either. Ertapenem minimum inhibitory concentration (MIC) values varied from $1 \mathrm{mg} / \mathrm{L}$ to $>4 \mathrm{mg} / \mathrm{L}$, with $\mathrm{MIC}_{50}$ value of $>4 \mathrm{mg} / \mathrm{L}$. Imipenem did not look any more promising, with an $\mathrm{MIC}_{50}$ value $>8 \mathrm{mg} / \mathrm{L}$. Of note, 99 of the 135 isolates carried additional genes encoding other ESBLs, with CTX-M being the most common, followed by SHV. Aztreonam is expected to be stable against the MBLs. ${ }^{9}$ It is thought that the chemical structure of aztreonam does not allow adequate molecular interaction with the active site of MBLs, and therefore, hydrolysis of aztreonam does not occur. ${ }^{38}$ However, because of the additional beta-lactamases and other resistance mechanisms often carried by these organisms, in vitro susceptibility is not always demonstrated to aztreonam. ${ }^{39}$ The addition of the beta-lactamase inhibitor avibactam to aztreonam often restores activity of aztreonam against such NDM-carrying organisms. Another study examining isolates from India and the UK confirmed high rates of resistance to carbapenems, cephalosporins, and other betalactams (including aztreonam), quinolones, and aminoglycosides..$^{10}$ Colistin was reported to have good in vitro activity against these isolates ( $89 \%-100 \%$ susceptibility),${ }^{10}$ but when tested in a murine lung infection model using susceptible 
isolates, it produced variable results. ${ }^{40}$ Tigecycline had in vitro activity as well $(56 \%-67 \% \text { susceptibility })^{10}$ and seemed to have more reliable activity in a murine lung infection against susceptible isolates. ${ }^{40}$ However, tigecycline against nonfermenting Gram-negative organisms seems to fall to $15 \%$, as compared to $60 \%$ susceptibility against Enterobacteriaceae, as reported by Jain et al. ${ }^{41}$ Fosfomycin is another antimicrobial to consider; susceptibility of NDM-producing organisms to fosfomycin has been reported in the literature to be $60.5 \%{ }^{41}$ to $78 \% .{ }^{42}$ The various pieces published that describe in vitro susceptibility mirror the susceptibilities seen in case reports, thus confirming consistency of in vitro reports, but further highlight the clinical response discrepancies.

Eravacycline is a new fluorocycline antibiotic currently in the development for treatment of infections caused by multidrug-resistant organisms. ${ }^{43}$ In a study investigating in vitro activity of eravacycline, five isolates showing nonsusceptibility to third-generation cephalosporins were confirmed to produce NDM. Of these five isolates, two (both Escherichia coli) had an MIC $\leq 0.5 \mu \mathrm{g} / \mathrm{mL}$ and three (all $K$. pneumoniae) had an MIC of $1-2 \mu \mathrm{g} / \mathrm{mL}$. Another potential advantage of eravacycline is the availability of both parenteral and oral formulations, which could provide for convenient parenteral-to-oral therapy changes. ${ }^{44}$ Despite the small number of NDM-producing isolates evaluated and the lack of clinical data, this study provides hope for another potential drug against NDM.

In vitro efficacy of combination therapy has also been evaluated against two NDM-producing $K$. pneumoniae strains. ${ }^{45}$ In a study done by Tangden et al, despite both strains being resistant to fosfomycin, a combination of fosfomycin and colistin was found to have both bactericidal and synergistic activities after 24 hours. Similar activity was seen with a combination of rifampin, meropenem, and colistin despite both strains being nonsusceptible to rifampin or meropenem alone. A combination of fosfomycin, meropenem, and colistin had both bactericidal and synergistic activities against one strain, but lacked bactericidal activity against the other strain. Bacterial regrowth during the 24-hour period was observed for colistin-containing combinations (as well as with colistin alone), but clinical relevance of this is yet to be determined. Another larger study looked for synergistic antimicrobial combination in $28 \mathrm{NDM}$ producers with paired combinations of colistin, fosfomycin, and tigecycline. ${ }^{46}$ In this particular study, synergy was rarely observed when colistin was paired with another drug. In this study, no antagonism was observed, and most antibiotic pairs did not have any interaction. However, another study investigating tigecycline and colistin combinations did identify antagonism when the two agents were combined..$^{47}$ Further studies are warranted to clarify the clinical significance of the interactions seen in these studies, particularly as it relates to possible antagonism. As it stands, available in vitro data for combination therapy also fails to provide insight into the unexpected good clinical outcomes seen in the literature.

\section{In vivo studies: reconciling discordance with in vitro findings}

Despite the grim outlook on therapy provided by in vitro data, in vivo data from animal studies paints a different picture in terms of antimicrobial options and potentially explains the discordant results of human clinical data. One study compared humanized doses of ceftazidime versus ceftazidime with avibactam against isolates producing NDM, as well as other beta-lactamases..$^{48}$ In vitro susceptibility testing to ceftazidime, avibactam, and the combination of ceftazidime/avibactam showed that all NDM-producing isolates were resistant to the tested compounds. Therefore, it was unexpected when humanized exposures of both ceftazidime alone and ceftazidime in combination with avibactam had activity against NDM-producing isolates in a murine thigh infection model (Figure 2). Ceftazidime alone showed a 1.4log reduction against an isogenic strain harboring NDM-1, whereas only modest to no activity was noted against clinical strains. The addition of avibactam to ceftazidime restored activity against all the tested strains, showing $0.61-1.42-\log$ reductions in bacterial growth. Since ceftazidime was active against the isogenic NDM harboring the single enzyme, it was not surprising that the addition of avibactam essentially eliminated the impact of other beta-lactamases, preserving ceftazidime's activity against the clinical isolates. These data suggest that the magnitude of the in vivo expression of NDM beta-lactamase is not large enough in the context of conventional exposure to ceftazidime as used in the clinical setting. It also highlights that genotypic testing only for NDM may not be sufficient for determining clinical response to therapy.

Carbapenems provide another example of discordance between in vitro data and in vivo data. A murine thigh infection model performed by Wiskirchen et al compared efficacy of humanized, high-dose, prolonged-infusion doripenem, and ertapenem against NDM-producing strains. ${ }^{49}$ An isogenic NDM-carrying $K$. pneumoniae strain as well as four clinical NDM-carrying strains all showed $>1-\log$ reduction in bacterial density with carbapenem therapy in an immunocompetent murine thigh infection model (Figure 3). The exception was one clinical strain with a doripenem $\mathrm{MIC}>32 \mu \mathrm{g} / \mathrm{mL}$, which showed only a modest decrease in bacterial density. This 


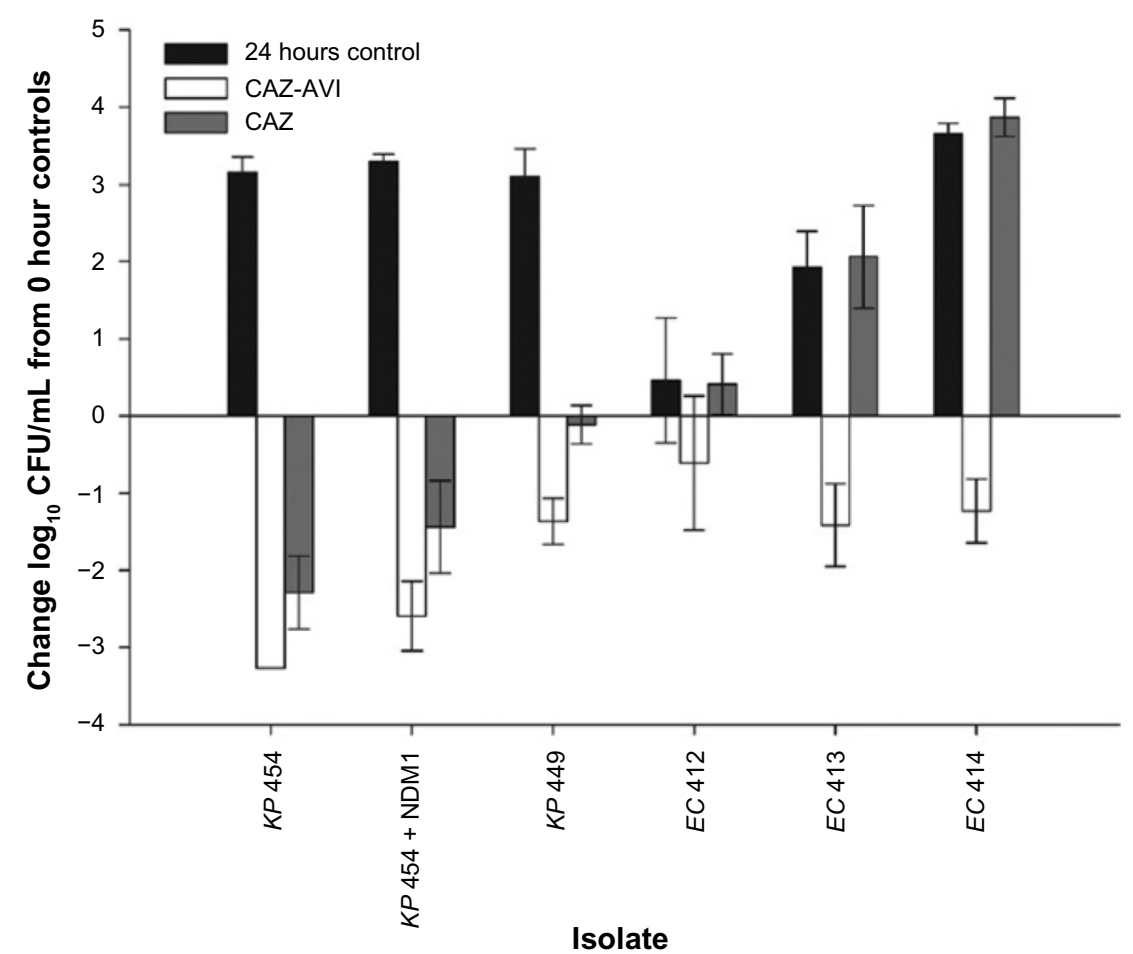

Figure 2 Comparative efficacies of human-simulated regimens of CAZ-AVI and CAZ alone against NDM-carrying EC and KP, and an isogenic NDM-I pair in the neutropenic murine thigh infection model.

Note: Reproduced with permission from the American Society for Microbiology. Copyright @ American Society for Microbiology. Wiskirchen DE, Nordmann P, Crandon JL, Nicolau DP. Efficacy of humanized carbapenem exposures against New Delhi metallo-beta-lactamase (NDM-I)-producing Enterobacteriaceae in a murine infection model. Antimicrob Agents Chemother. 2013;57(8):3936-3940.49

Abbreviations: CAZ, ceftazidime; CAZ-AVI, ceftazidime-avibactam; CFU, colony-forming units; EC, Escherichia coli; KP, Klebsiella pneumoniae; NDM, New Delhi metallobeta-lactamase.

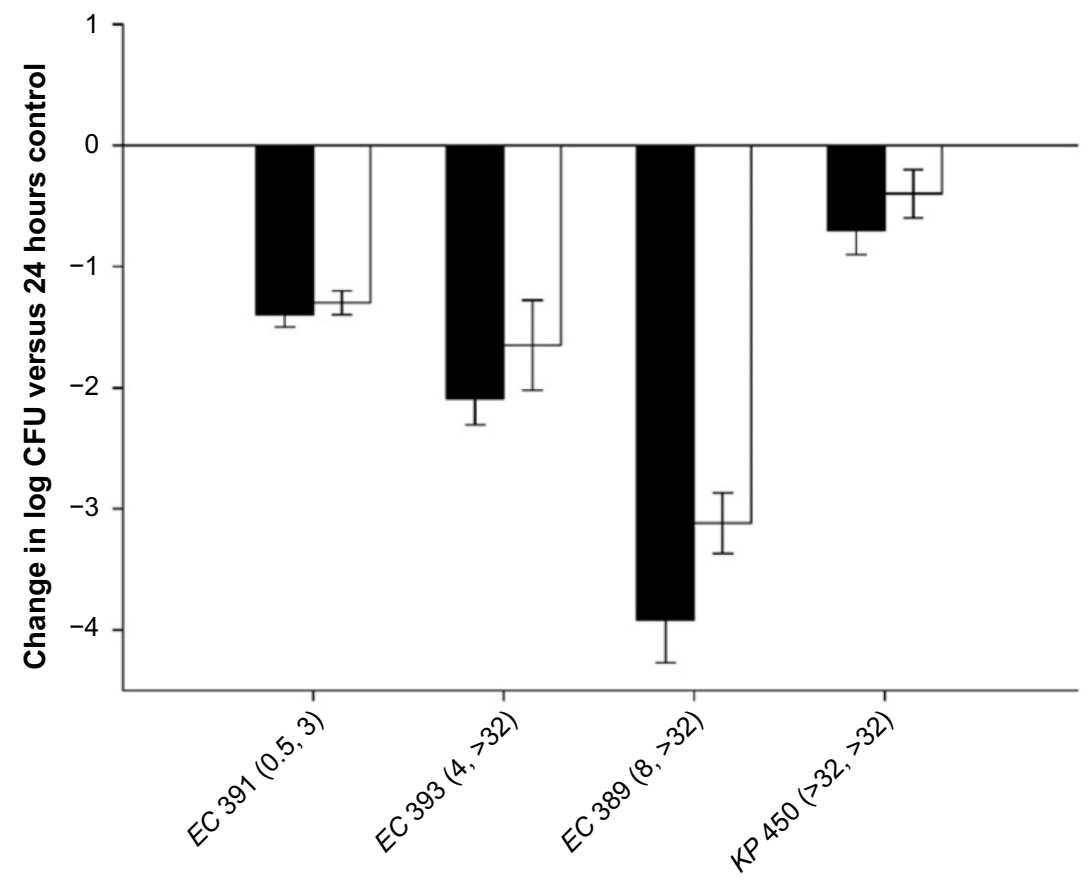

Isolate (DOR MIC, ERT MIC, $\mu \mathrm{g} / \mathrm{mL}$ )

Figure 3 Efficacy of human-simulated regimens of doripenem at $2 \mathrm{~g}$ every 8 hours as a 4-hour infusion (black bars) or ertapenem at I g every 24 hours (white bars) against four clinical NDM-I-producining Enterobacteriaceae.

Note: Reproduced with permission from the American Society for Microbiology. Copyright @ American Society for Microbiology. Bercot B, Poirel L, Dortet L, Nordmann P. In vitro evaluation of antibiotic synergy for NDM-I-producing Enterobacteriaceae. J Antimicrob Chemother. 20I I;66(I0):2295-2297. ${ }^{46}$

Abbreviations: CFU, colony-forming units; DOR, doripenem; EC, Escherichia coli; ERT, ertapenem; KP, Klebsiella pneumoniae; NDM, New Delhi metallo-beta-lactamase. 
successful reduction in bacterial density was shown again in the same study using two clinical strains in a neutropenic murine thigh infection model, and the effect was shown to be sustained out to 72 hours in an extended immunocompetent murine model. The efficacy of carbapenems against NDM producers was confirmed in a second study done by Wiskirchen et al in both immunocompetent and neutropenic murine thigh infection models (Figure 4).$^{50}$ This second study also confirmed the need for higher doripenem doses; a dose providing the human exposure of $2 \mathrm{~g}$ every 8 hours infused over 4 hours consistently produced numerically higher bacterial reductions as compared to a standard dose of $500 \mathrm{mg}$ given every 8 hours. This difference in bacterial reductions between the two regimens was statistically different in two of the four tested strains. Both studies also noted efficacy with carbapenems despite high MIC values and unmet pharmacokinetic/pharmacodynamic target for success $(40 \% f \mathrm{~T}>$ MIC). ${ }^{49,50}$ NDM-producing organisms are not the first MBLs to demonstrate a mismatch between in vitro and in vivo efficacies. Enterobacteriaceae carrying the VIM MBL also show in vitro resistance to carbapenems, and yet, meropenem was able to produce a substantial reduction in bacterial density in a neutropenic murine thigh infection model (American Society for Microbiology, Washington, DC, data on file, 2015). Taken together, these studies suggest that carbapenems may make valuable contributions to fighting infections caused by NDM-producing organisms, and consideration should be given to utilizing these agents, especially when the organism fails to show susceptibility to other agents.

Aztreonam is expected to be stable against NDM-producing organisms, but is often not susceptible in vitro due to the presence of other beta-lactamases. ${ }^{9}$ Conversely, the beta-lactamase inhibitor avibactam is protective against most other betalactamases, the exception being other MBLs. ${ }^{39}$ Activity of the two compounds together has been confirmed both in vitro and in vivo. ${ }^{39}$ A neutropenic murine thigh infection model utilizing human-simulated exposures of aztreonam alone and in combination with avibactam was performed. ${ }^{51}$ It showed aztreonam alone had poor activity against the 14 NDM-carrying Enterobacteriaceae tested, but the combination had excellent antibacterial activity (Figure 5). All the animals in the combination group remained alive, whereas deaths were seen in the aztreonam
A

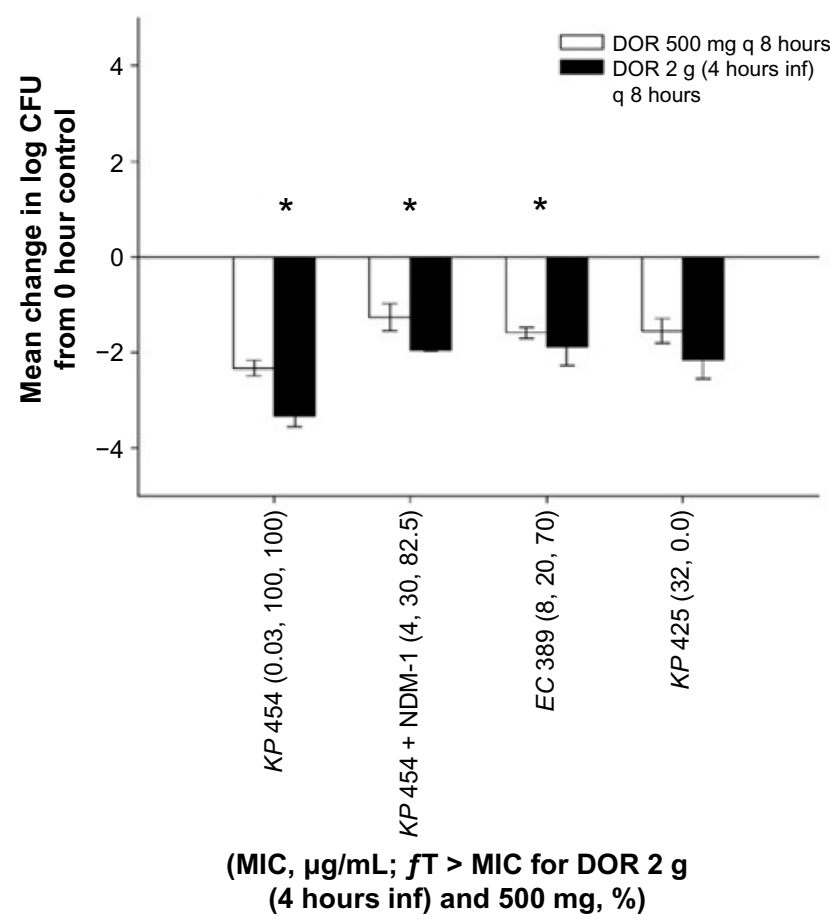

B

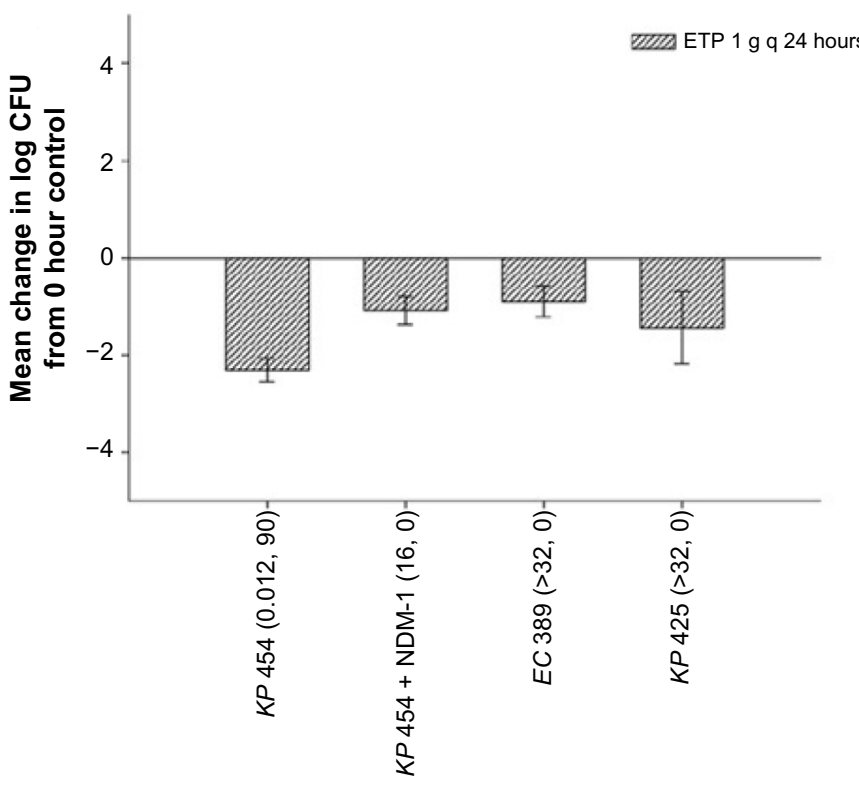

Isolates (MIC, $\mu \mathrm{g} / \mathrm{mL} ; f \mathrm{~T}>\mathrm{MIC}, \%$ )

Figure 4 Efficacies of human-simulated regimens of $500 \mathrm{mg}$ of DOR given every 8 hours and $2 \mathrm{~g}$ of DOR given every 8 hours as a 4 -hour infusion (A) and I g of ETP given every 24 hours $(\mathbf{B})$ in a neutropenic murine thigh infection model.

Note: *Denote a statistically higher efficacy of the higher DOR dose as compared to the lower DOR dose. Reproduced with permission from the American Society for Microbiology. Copyright (C) American Society for Microbiology. Wiskirchen DE, Nordmann P, Crandon JL, Nicolau DP. In vivo efficacy of human simulated regimens of carbapenems and comparator agents against NDM-I-producing Enterobacteriaceae. Antimicrob Agents Chemother. 20I4;58(3): 167I-I677. ${ }^{50}$

Abbreviations: CFU, colony-forming units; DOR, doripenem; EC, Escherichia coli; ETP, ertapenem; KP, Klebsiella pneumoniae. 


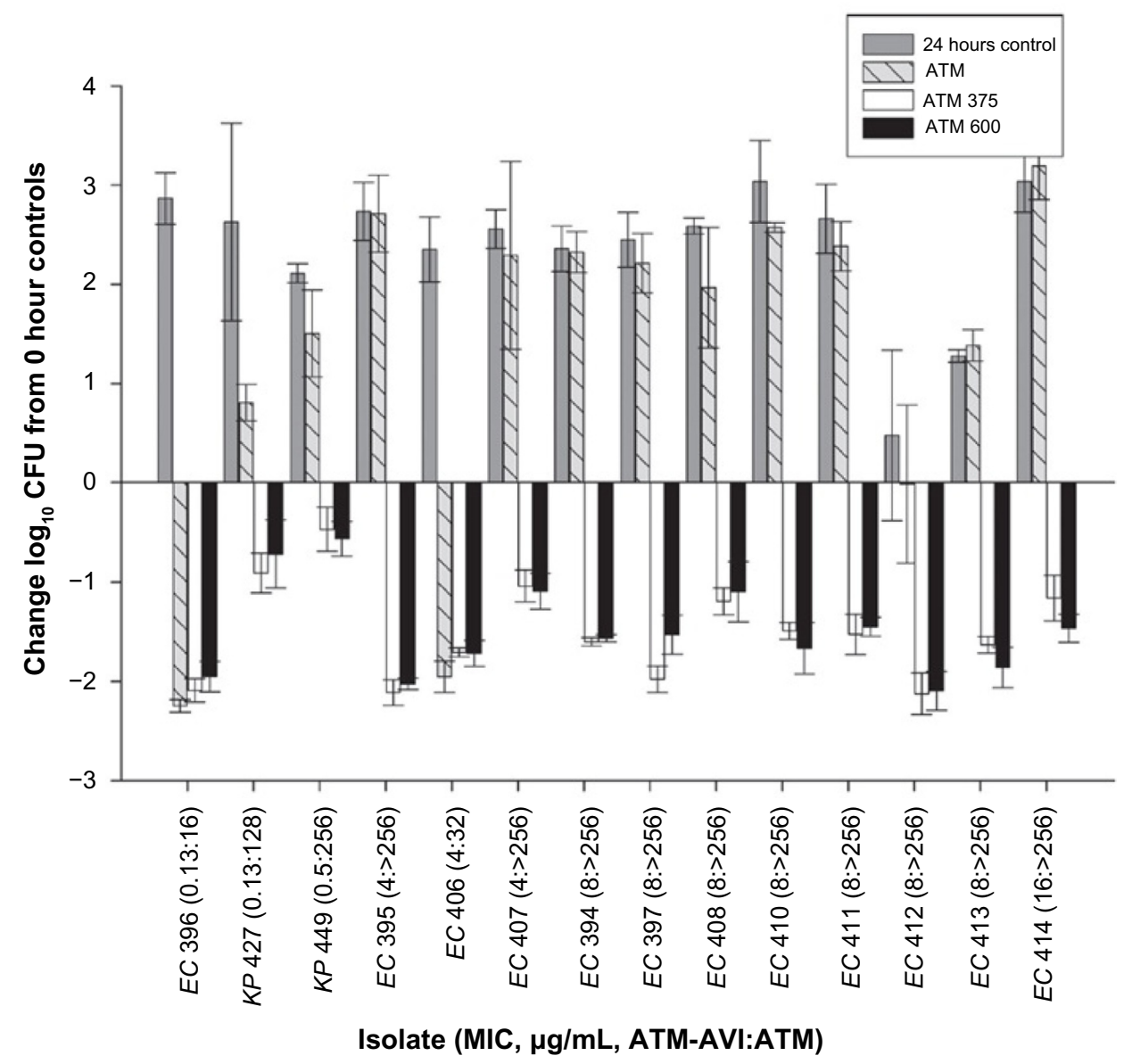

Figure 5 Comparative efficacy of a human-simulated dose of 2,000 mg aztreonam q6h (I-hour infusion) as monotherapy or combined with 375 mg avibactam q6h (ATM-AVI $375 \mathrm{mg}$ ) or $600 \mathrm{mg}$ avibactam q6h (ATM-AVI $600 \mathrm{mg}$ ) against Enterobacteriaceae in a neutropenic-mouse thigh infection.

Note: Reproduced with permission from the American Society for Microbiology. Copyright @ $\subseteq$ American Society for Microbiology. Crandon JL, Nicolau DP. Human simulated studies of aztreonam and aztreonam-avibactam to evaluate activity against challenging gram-negative organisms, including metallo-beta-lactamase producers. Antimicrob Agents Chemother. 2013;57(7):3299-3306. ${ }^{51}$

Abbreviations: ATM, aztreonam; AVI, avibactam; CFU, colony-forming units; EC, Escherichia coli; KP, Klebsiella pneumoniae.

and the control group. Based on these data, the combination of aztreonam and avibactam seems like a viable option for the treatment of infections caused by NDM-producing organisms, particularly when other beta-lactamases may be present.

These animal data match more closely with the observations of clinical outcomes. The mismatch between observed and expected efficacy highlighted by these animal studies brings hope that new therapy options may be uncovered from previously abandoned therapies. These data also underscore the need to further explore and identify potential therapies, whether they are in the form of new antimicrobials or old antimicrobials. It also highlights the need to not only properly identify the presence of NDM but also the presence of other beta-lactamases.

\section{Conclusion}

The current state of evidence demonstrates that in the case of NDM producers, in vitro results do not appear to translate into clinical results as expected. In the absence of larger trials, numerous case reports demonstrated favorable clinical outcomes despite mismatches between antimicrobials and susceptibility results. Moreover, carbapenems have unexpectedly demonstrated utility both in animal studies and in the clinical setting, despite in vitro hydrolysis. Since most case reports utilize combination therapy with good outcomes, it seems reasonable that combination therapy using sufficient exposure of the selected compound is the preferred strategy against NDM producers. Furthermore, available evidence suggests that carbapenems should continue to be included in the armamentarium against such infections.

\section{Disclosure}

MD Nailor has been involved in consulting/grants and speaker bureaus for Astellas and Merck pharmaceutical 
companies. DP Nicolau has been involved in consulting/ grants and speaker bureaus for AstraZeneca, Cubist, Merck, Tetraphase, and Actavis pharmaceutical companies. The other authors report no conflicts of interest in this work.

\section{References}

1. Queenan AM, Bush K. Carbapenemases: the versatile beta-lactamases. Clin Microbiol Rev. 2007;20(3):440-458.

2. Cornaglia G, Giamarellou H, Rossolini GM. Metallo-beta-lactamases: a last frontier for beta-lactams? Lancet Infect Dis. 2011;11(5): 381-393.

3. Yong D, Toleman MA, Giske CG, et al. Characterization of a new metallo-beta-lactamase gene, bla(NDM-1), and a novel erythromycin esterase gene carried on a unique genetic structure in Klebsiella pneumoniae sequence type 14 from India. Antimicrob Agents Chemother. 2009;53(12):5046-5054.

4. Dortet L, Poirel L, Nordmann P. Worldwide dissemination of the NDM-type carbapenemases in gram-negative bacteria. Biomed Res Int. 2014;2014:249856.

5. Wang X, Li H, Zhao C, et al. Novel NDM-9 metallo-beta-lactamase identified from a ST107 Klebsiella pneumoniae strain isolated in China. Int J Antimicrob Agents. 2014;44(1):90-91.

6. Zou D, Huang Y, Zhao X, et al. A novel New Delhi metallo-betalactamase variant, NDM-14, isolated in a Chinese hospital possesses increased enzymatic activity against carbapenems. Antimicrob Agents Chemother. 2015;59(4):2450-2453.

7. Nordmann P, Boulanger AE, Poirel L. NDM-4 metallo-beta-lactamase with increased carbapenemase activity from Escherichia coli. Antimicrob Agents Chemother. 2012;56(4):2184-2186.

8. Castanheira M, Deshpande LM, Farrell SE, Shetye S, Shah N, Jones RN. Update on the prevalence and genetic characterization of NDM-1producing Enterobacteriaceae in Indian hospitals during 2010. Diagn Microbiol Infect Dis. 2013;75(2):210-213.

9. Biedenbach D, Bouchillon S, Hackel M, et al. Dissemination of NDM metallo-beta-lactamase genes among clinical isolates of Enterobacteriaceae collected during the SMART global surveillance study from 2008 to 2012. Antimicrob Agents Chemother. 2015;59(2):826-830.

10. Kumarasamy KK, Toleman MA, Walsh TR, et al. Emergence of a new antibiotic resistance mechanism in India, Pakistan, and the UK: a molecular, biological, and epidemiological study. Lancet Infect Dis. 2010;10(9):597-602.

11. Mizuno Y, Yamaguchi T, Matsumoto T. A first case of New Delhi metallo-beta-lactamase-7 in an Escherichia coli ST648 isolate in Japan. $J$ Infect Chemother. 2014;20(12):814-816.

12. Halaby T, Reuland AE, Al Naiemi N, et al. A case of New Delhi metallo-beta-lactamase 1 (NDM-1)-producing Klebsiella pneumoniae with putative secondary transmission from the Balkan region in the Netherlands. Antimicrob Agents Chemother. 2012;56(5):2790-2791.

13. Poirel L, Lagrutta E, Taylor P, Pham J, Nordmann P. Emergence of metallobeta-lactamase NDM-1-producing multidrug-resistant Escherichia coli in Australia. Antimicrob Agents Chemother. 2010; 54(11):4914-4916.

14. Tzouvelekis LS, Markogiannakis A, Psichogiou M, Tassios PT, Daikos GL. Carbapenemases in Klebsiella pneumoniae and other Enterobacteriaceae: an evolving crisis of global dimensions. Clin Microbiol Rev. 2012;25(4): 682-707.

15. Miriagou V, Cornaglia G, Edelstein M, et al. Acquired carbapenemases in gram-negative bacterial pathogens: detection and surveillance issues. Clin Microbiol Infect. 2010;16(2):112-122.

16. Nordmann P, Poirel L, Dortet L. Rapid detection of carbapenemase-producing Enterobacteriaceae. Emerg Infect Dis. 2012;18(9): 1503-1507.

17. Clinical and Laboratory Standards Institute [Internet page]. CLSI Publishes New Antimicrobial Susceptibility Testing Standards. 2015. Available from: http://clsi.org/blog/2015/01/08/clsi-publishes-new-antimicrobial-susceptibility-testing-standards/. Accessed May 8, 2015.
18. Datta S, Roy S, Chatterjee S, et al. A five-year experience of carbapenem resistance in Enterobacteriaceae causing neonatal septicaemia: predominance of NDM-1. PLoS One. 2014;9(11):e112101.

19. Daikos GL, Petrikkos P, Psichogiou M, et al. Prospective observational study of the impact of VIM-1 metallo-beta-lactamase on the outcome of patients with Klebsiella pneumoniae bloodstream infections. Antimicrob Agents Chemother. 2009;53(5):1868-1873.

20. Munoz-Price LS, Poirel L, Bonomo RA, et al. Clinical epidemiology of the global expansion of Klebsiella pneumoniae carbapenemases. Lancet Infect Dis. 2013;13(9):785-796.

21. Chihara S, Okuzumi K, Yamamoto Y, Oikawa S, Hishinuma A. First case of New Delhi metallo-beta-lactamase 1-producing Escherichia coli infection in Japan. Clin Infect Dis. 2011;52(1):153-154.

22. Pasteran F, Mora MM, Albornoz E, et al. Emergence of genetically unrelated NDM-1-producing Acinetobacter pittii strains in Paraguay. J Antimicrob Chemother. 2014;69(9):2575-2578.

23. Sidjabat H, Nimmo GR, Walsh TR, et al. Carbapenem resistance in Klebsiella pneumoniae due to the New Delhi metallo-beta-lactamase. Clin Infect Dis. 2011;52(4):481-484.

24. Seija V, Medina Presentado JC, Bado I, et al. Sepsis caused by New Delhi metallo-beta-lactamase (blaNDM-1) and qnrD-producing Morganella morganii, treated successfully with fosfomycin and meropenem: case report and literature review. Int J Infect Dis. 2015;30:20-26.

25. Flateau C, Janvier F, Delacour H, et al. Recurrent pyelonephritis due to NDM-1 metallo-beta-lactamase producing Pseudomonas aeruginosa in a patient returning from Serbia, France, 2012. Euro Surveill. 2012; 17(45):20311.

26. Nagar A, Yew P, Ong G, et al. Two cases of importation of New Delhi metallo-beta-lactamase 1 into Northern Ireland. Ulster Med J. 2012; 81(3):154-155.

27. Stone NR, Woodford N, Livermore DM, et al. Breakthrough bacteraemia due to tigecycline-resistant Escherichia coli with New Delhi metallo-betalactamase (NDM)-1 successfully treated with colistin in a patient with calciphylaxis. J Antimicrob Chemother. 2011;66(11): 2677-2678.

28. Chien JM, Koh TH, Chan KS, Chuah TH, Tan TT. Successful treatment of NDM-1 Klebsiella pneumoniae bacteraemia in a neutropenic patient. Scand J Infect Dis. 2012;44(4):312-314.

29. Pasteran F, Albornoz E, Faccone D, et al. Emergence of NDM-1producing Klebsiella pneumoniae in Guatemala. J Antimicrob Chemother. 2012;67(7):1795-1797.

30. Escobar Pérez JA, Olarte Escobar NM, Castro-Cardozo B, et al. Outbreak of NDM-1-producing Klebsiella pneumoniae in a neonatal unit in Colombia. Antimicrob Agents Chemother. 2013;57(4): 1957-1960.

31. Pannaraj PS, Bard JD, Cerini C, Weissman SJ. Pediatric carbapenemresistant Enterobacteriaceae in Los Angeles, California, a highprevalence region in the United States. Pediatr Infect Dis J. 2015;34(1): 11-16.

32. Samuelsen O, Thilesen CM, Heggelund L, Vada AN, Kummel A, Sundsfjord A. Identification of NDM-1-producing Enterobacteriaceae in Norway. J Antimicrob Chemother. 2011;66(3):670-672.

33. Poirel L, Ros A, Carricajo A, et al. Extremely drug-resistant Citrobacter freundii isolate producing NDM-1 and other carbapenemases identified in a patient returning from India. Antimicrob Agents Chemother. 2011;55(1):447-448.

34. Kulkova N, Babalova M, Sokolova J, Krcmery V. First report of New Delhi metallo-beta-lactamase-1-producing strains in Slovakia. Microb Drug Resist. 2015;21(1):117-120.

35. Chan HL, Poon LM, Chan SG, Teo JW. The perils of medical tourism: NDM-1-positive Escherichia coli causing febrile neutropenia in a medical tourist. Singapore Med J. 2011;52(4):299-302.

36. Carattoli A, Fortini D, Galetti R, et al. Isolation of NDM-1-producing Pseudomonas aeruginosa sequence type ST235 from a stem cell transplant patient in Italy, May 2013. Euro Surveill. 2013;18(46):20633.

37. Poirel L, Ozdamar M, Ocampo-Sosa AA, Turkoglu S, Ozer UG, Nordmann P. NDM-1-producing Klebsiella pneumoniae now in Turkey. Antimicrob Agents Chemother. 2012;56(5):2784-2785. 
38. Drawz SM, Papp-Wallace KM, Bonomo RA. New beta-lactamase inhibitors: a therapeutic renaissance in an MDR world. Antimicrob Agents Chemother. 2014;58(4):1835-1846.

39. Livermore DM, Mushtaq S, Warner M, et al. Activities of NXL104 combinations with ceftazidime and aztreonam against carbapenemaseproducing Enterobacteriaceae. Antimicrob Agents Chemother. 2011; 55(1):390-394.

40. Docobo-Pérez F, Nordmann P, Domínguez-Herrera J, et al. Efficacies of colistin and tigecycline in mice with experimental pneumonia due to NDM-1-producing strains of Klebsiella pneumoniae and Escherichia coli. Int J Antimicrob Agents. 2012;39(3):251-254.

41. Jain A, Hopkins KL, Turton J, et al. NDM carbapenemases in the United Kingdom: an analysis of the first 250 cases. J Antimicrob Chemother. 2014;69(7):1777-1784.

42. Kaase M, Szabados F, Anders A, Gatermann SG. Fosfomycin susceptibility in carbapenem-resistant Enterobacteriaceae from Germany. J Clin Microbiol. 2014;52(6):1893-1897.

43. Sutcliffe JA, O'Brien W, Fyfe C, Grossman TH. Antibacterial activity of eravacycline (TP-434), a novel fluorocycline, against hospital and community pathogens. Antimicrob Agents Chemother. 2013;57(11): 5548-5558.

44. Tetraphase Pharmaceuticals Pipeline: Eravacycline [Internet page]. Tetraphase Pharmaceuticals. Accessed from: http://tphase.com/pipeline/ eravacycline. Accessed May 7, 2015.

45. Tangden T, Hickman RA, Forsberg P, Lagerback P, Giske CG, Cars O. Evaluation of double- and triple-antibiotic combinations for VIMand NDM-producing Klebsiella pneumoniae by in vitro time-kill experiments. Antimicrob Agents Chemother. 2014;58(3):1757-1762.

46. Bercot B, Poirel L, Dortet L, Nordmann P. In vitro evaluation of antibiotic synergy for NDM-1-producing Enterobacteriaceae. J Antimicrob Chemother. 2011;66(10):2295-2297.

47. Albur M, Noel A, Bowker K, MacGowan A. Bactericidal activity of multiple combinations of tigecycline and colistin against NDM1-producing Enterobacteriaceae. Antimicrob Agents Chemother. 2012;56(6):3441-3443.

48. MacVane SH, Crandon JL, Nichols WW, Nicolau DP. Unexpected in vivo activity of ceftazidime alone and in combination with avibactam against New Delhi metallo-beta-lactamase-producing Enterobacteriaceae in a murine thigh infection model. Antimicrob Agents Chemother. 2014;58(11):7007-7009.

49. Wiskirchen DE, Nordmann P, Crandon JL, Nicolau DP. Efficacy of humanized carbapenem exposures against New Delhi metallo-betalactamase (NDM-1)-producing Enterobacteriaceae in a murine infection model. Antimicrob Agents Chemother. 2013;57(8):3936-3940.

50. Wiskirchen DE, Nordmann P, Crandon JL, Nicolau DP. In vivo efficacy of human simulated regimens of carbapenems and comparator agents against NDM-1-producing Enterobacteriaceae. Antimicrob Agents Chemother. 2014;58(3):1671-1677.

51. Crandon JL, Nicolau DP. Human simulated studies of aztreonam and aztreonam-avibactam to evaluate activity against challenging gramnegative organisms, including metallo-beta-lactamase producers. Antimicrob Agents Chemother. 2013;57(7):3299-3306.
52. Oteo J, Domingo-García D, Fernández-Romero S, et al. Abdominal abscess due to NDM-1-producing Klebsiella pneumoniae in Spain. J Med Microbiol. 2012;61(pt 6):864-867.

53. Green DA, Srinivas N, Watz N, Tenover FC, Amieva M, Banaei N. A pediatric case of New Delhi metallo-beta-lactamase-1-producing Enterobacteriaceae in the United States. Pediatr Infect Dis J. 2013;32(11):1291-1294.

54. Mochon AB, Garner OB, Hindler JA, et al. New Delhi metallo-betalactamase (NDM-1)-producing Klebsiella pneumoniae: case report and laboratory detection strategies. J Clin Microbiol. 2011;49(4): 1667-1670.

55. Rogers BA, Sidjabat HE, Silvey A, et al. Treatment options for New Delhi metallo-beta-lactamase-harboring Enterobacteriaceae. Microb Drug Resist. 2013;19(2):100-103.

56. Hoang TH, Wertheim H, Minh NB, et al. Carbapenem-resistant Escherichia coli and Klebsiella pneumoniae strains containing New Delhi metallo-beta-lactamase isolated from two patients in Vietnam. J Clin Microbiol. 2013;51(1):373-374.

57. McDermott H, Morris D, McArdle E, et al. Isolation of NDM-1producing Klebsiella pnemoniae in Ireland, Jul 2011. Euro Surveill. 2012;17(7):20087.

58. Carvalho-Assef AP, Pereira PS, Albano RM, et al. Isolation of NDMproducing Providencia rettgeri in Brazil. J Antimicrob Chemother. 2013;68(12):2956-2957.

59. Waterman PE, McGann P, Snesrud E, et al. Bacterial peritonitis due to Acinetobacter baumannii sequence type 25 with plasmid-borne New Delhi metallo-beta-lactamase in Honduras. Antimicrob Agents Chemother. 2013;57(9):4584-4586.

60. Lai CC, Lin TL, Tseng SP, et al. Pelvic abscess caused by New Delhi metallo-beta-lactamase-1-producing Klebsiella oxytoca in Taiwan in a patient who underwent renal transplantation in China. Diagn Microbiol Infect Dis. 2011;71(4):474-475.

61. Peirano G, Ahmed-Bentley J, Woodford N, Pitout JD. New Delhi metallo-beta-lactamase from traveler returning to Canada. Emerg Infect Dis. 2011;17(2):242-244.

62. Barrios H, Silva-Sanchez J, Reyna-Flores F, et al. Detection of a NDM1-producing Klebsiella pneumoniae (ST22) clinical isolate at a pediatric hospital in Mexico. Pediatr Infect Dis J. 2014;33(3):335.

63. Mulvey MR, Grant JM, Plewes K, Roscoe D, Boyd DA. New Delhi metallo-beta-lactamase in Klebsiella pneumoniae and Escherichia coli. Canada. Emerg Infect Dis. 2011;17(1):103-106.

64. Poirel L, Benouda A, Hays C, Nordmann P. Emergence of NDM-1producing Klebsiella pneumoniae in Morocco. JAntimicrob Chemother. 2011;66(12):2781-2783.

65. Khajuria A, Praharaj AK, Kumar M, Grover N. A case of septicemia due to Chryseobacterium indologenes producing blaNDM-1. Avicenna J Med. 2014;4(3):71-73.
Infection and Drug Resistance

\section{Publish your work in this journal}

Infection and Drug Resistance is an international, peer-reviewed openaccess journal that focuses on the optimal treatment of infection (bacterial, fungal and viral) and the development and institution of preventive strategies to minimize the development and spread of resistance. The journal is specifically concerned with the epidemiology of antibiotic

\section{Dovepress}

resistance and the mechanisms of resistance development and diffusion in both hospitals and the community. The manuscript management system is completely online and includes a very quick and fair peerreview system, which is all easy to use. Visit http://www.dovepress.com/ testimonials.php to read real quotes from published authors. 